\title{
Smart Logistics: Blockchain trends and applications
}

\author{
Yassine Issaoui $^{a *}$, Azeddine Khiat ${ }^{a}$, Ayoub Bahnasse ${ }^{b}$, Hassan Ouajji $^{a}$ \\ ${ }^{a}$ Lab SSDIA, University Hassan II of Casablanca, Morocco \\ ${ }^{b}$ ENSAM Casablanca, University Hassan II of Casablanca, Morocco
}

\begin{abstract}
The recent increase of new technologies and their involvement into all management processes call into question the smart logistics current models, in which massive amounts of data is collected and controlled. Smart Logistics is considered as fundamental pillar of the 4th industrial revolution 'industry 4.0'. This revolution is based on different concepts including the blockchain technology. Blockchain remains one of the buzzwords in the technological world. So that all sectors are focus on concrete use cases. However, few actors can boast of having devised revolutionary solutions. For good reasons, blockchain technology is still very complex to understand. The purpose of this study is to define the various applications of Blockchain in Smart Logistics, as well as to present concrete examples of these applications. This work was done by classifying the applications according to four clusters: Information, Transport, Finance, and Management, in addition to presenting the applications of each cluster.
\end{abstract}

Keywords: Blockchain, Smart Logistics, Smart Constracts, Smart Supply Chain Management.

\section{Introduction}

Digitization and the growth of new technologies such as the "Internet of Things", 3D printing, robotics, predictive analytics and artificial intelligence, have a significant impact on the processes all along the supply chain. During this process, decision-making, at the stages of the manufacturing and distribution process, can be accomplished using sophisticated and complex analyzes that decrease the human intervention. Two simple things prove that using a smart supply chain is a persistent benefit are: cost and space savings. Actually, the smart logistics system is a self-organizing and self-optimizing system, in which, the data from the connected sensors can be integrated with the data based on user preferences.

In fact, Smart logistics remains a fairly complex concept. It can be used in geographically dispersed areas, for the acquisition of raw materials of the highest quality, as well as the lowest cost, or the marketing of products to reach a large number of consumers. The industry 4.0 paradigm is characterized by the use of new technologies such as IoT, 5G, sensors, RFID cards, smart products, actuators, and intelligent machines. Consequently, a large amount of data will be generated and new challenges will emerge. This highlights the issues of confidence, lack of interoperability, as well as many security and data reliability issues that form major challenges to face the implementation of such infrastructures problems, also, fraud, theft, loss of data, the diversity of marketing policies, the multitude of expenses of financial transactions and goods. Although, the transparency of the supply chain, it remains one of the most important and difficult to reach areas for logistics and supply chain management [1]. Therefore, a simple, secure, fast sharing of information or products, and funds was the need of almost all companies operating in this field.

As an emergent technology, Blockchain begins to appeal to smart logistics researchers. Thus, blockchain aims to increase the operational performance while ensuring the reliability and security of shared information. Blockchain technology first gained popularity as a management platform for Bitcoin, which is a digital cryptocurrency. In addition to the digital currency, blockchain is a new paradigm of computer science and data flows. For that, it has broad implications for the future development of supply chain management and logistics [2]. Blockchain technology can ensure data security, reliability, traceability, and authenticity, which will increase trust between supply chain actors and end consumer, by providing reliable information about the shared products through a public Blockchain.

Blockchain technology could simplify or even automate the exchange of information and generate greater trust between the various partners. It is then the whole supply chain which would gain in speed of execution. companies are slowly starting to deploy blockchain in their supply chain, although the results are still rare at the moment. In 2018, several industry alliances and associations were established to explore the potential for using this technology across logistics activities.

The main purpose of this paper is to examine the scope of Blockchain technology in the field of smart logistics. For this, we segmented our study into four sets. Firstly, Information; which consists of presenting the application of Blockchain for

${ }^{*}$ Corresponding author. Tel.: +00000000000000

Fax: +9876543210; E-mail: issaouiyassine818@gmail.com

(C) 2020 International Association for Sharing Knowledge and Sustainability.

DOI: $10.5383 / J U S P N .12 .02 .002$ 
the data collection, and the follow-up of the traceability. Secondly, the transport field which focuses on last-mile logistics. Thirdly, the application of Blockchain to the financial field, which is the sector of its first appearance. And finally, the management, and the presentation of the improvements brought by Blockchain technology to the process of smart logistics.

This paper is organized according to the following sections: Section 2 details the literature review. Section 3 focuses on Blockchain technology applications in the field of smart logistics. Section 4 focuses on the discussion of the results obtained. And, section 5 is devoted to the conclusion.

\section{Literature review}

\subsection{Smart Supply Chain Management}

The term Supply Chain Management was invented more than two decades ago [3]. Indeed, the supply chain has been defined according to different contexts. Quite simply, a supply chain is a systematic grouping of the set of controlled activities from the supply of raw materials to the delivery of finished products [4]. However, the recent supply chain requires an advanced level of intelligence to respond to the abrupt and sudden changes in the market [5]. In 2018, more attention has been paid to green technological innovations in order to be able to create an intelligent supply chain for competitive advantage and high caliber performance [6]. In the supply chain, companies are beginning to invest more in the creation of a sailed supply chain structure, which used to be considered as an operational activity that fulfills a particular task. Today, supply chains are fueled as competitive resources, but Butner [7] has explained the characteristics of the smart supply chain while looking for agility and sustainability. Kaur and Singh [8] have explained the importance of flexible but sustainable supply chain activities.

The supply chain includes several necessary steps. First, acquiring the raw materials by the producer. Then, performing the required transformations. Then, finally products shipping to the end consumer. In other words, the supply chain refers to a set of processes involved in sourcing, processing, and distributing products and services. Accordingly, supply chain management makes it possible to have the right item, in the right amount, at the right time, in the right place, with the right price, taking into consideration the right conditions for the right customer [9].

Due to different reasons such as complexity, uncertainty, and other factors, most supply chains are known for their numerous supply/demand mismatch problems, such as excess inventories, stockouts and delivery delays, which have long been popular research topics in the business management literature [10]. In addition, the business climate has become more competitive, customer demands are also more specific. These complexities and problems lead companies to look for solutions in order to improve their work processes as well as the adopted implementation methods. To effectively face the growing challenges, supply chains need to become much smarter [11]. To this end, companies need to improve their processes by integrating new information and communication technologies. In this context, the new industrial revolution called 'industry 4.0 ' in the daylight. This revolution takes full advantage of the improvements made in the IT, electronics, telecommunication, and mechanical fields. This industrial revolution has allowed the emergence of new paradigms such as smart supply chains, smart products, smart factories, and many other concepts. Smart supply chains are characterized mainly by the interconnection of internal objects, with stakeholders, as well as optimal decision making by intelligent systems, and process integration [12]. Thus, this transformation will principally enable channel managers, load optimization, speed and efficiency of processes and operations, customer satisfaction, and increased profitability.

\subsection{Smart logistics}

Currently, global logistics systems have a multitude of product variants. In this sense, different management methods have been derived. However, ordinary logistics systems are still unable to handle even more complex situations without increasing costs or decreasing quality [13]. To overcome these complexities, dynamic, customer-driven adaptation is required to achieve logistics goals, while providing real-time visibility to react to sudden changes [14]. Therefore, a corresponding Logistics 4.0 system is needed to resolve the failures that can influence the relationship between manufacturers and customers.

Obviously, logistics enables the management of the company's physical flows by including a set of activities, such as demand forecasting, sales planning, supply requirements, inventory management, materials handling packaging, order picking, and product distribution. For logistics, technological development and the appearance of the fourth industrial revolution contributed to the generation of several challenges. These can accelerate the integration of technology into all logistics processes. This has led to the emergence of a new concept called 'smart logistics' or 'logistics 4.0'.

According to McFarlane, smart logistics is about planning and controlling with smart tools and methods. he confirmed that the degree of intelligence depends on the applications and the methods used since the traceability of the products and the identification of the elements of its environment, until the detection of the problem, the choice and the automatic execution of the solution [15]. On the other hand, Uckelmann [16], was based on the concept of smart product and smart service to define the intelligent logistics like the use of the technology to obtain information on the flow of material, then on the treatment to monitoring, control, and other purposes. With intelligent asset tracking tools and equipment, all supply chains are becoming more efficient and effective by noting different changes:

- $\quad$ Significant end-to-end visibility;

- Improvement of product routing;

- Control and replenishment of inventories and mobile assets;

- Detailed management of marketing experience.

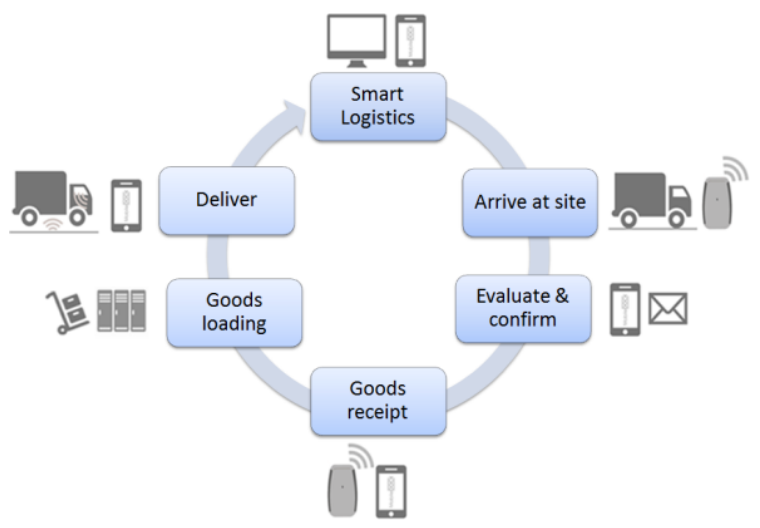

Fig. 1 : Smart Logistics steps 


\subsection{Blockchain}

Being an emerging technology, the Blockchain aims at storing and transmitting data in a secure, more transparent, and decentralized way. It is considered a distributed database, or public/private shared ledger of all digital events, that has been run and shared among agents participating in the blockchain [20].

Technically, Blockchain is a distributed system, containing all the transactions done since its start, in the form of blocks. These are constituted by the information sent by the users. These data transactions are secured by cryptographic algorithms. Blockchains can be generalized and used to implement a set of agreed rules that no one, neither users nor system operators, can break. They rely on a single platform of system architecture for multi-part applications requiring little mutual trust [21].

Blockchain technology is characterized by the decentralization of data by providing a higher level of data security. Confidence is one of the main consequence

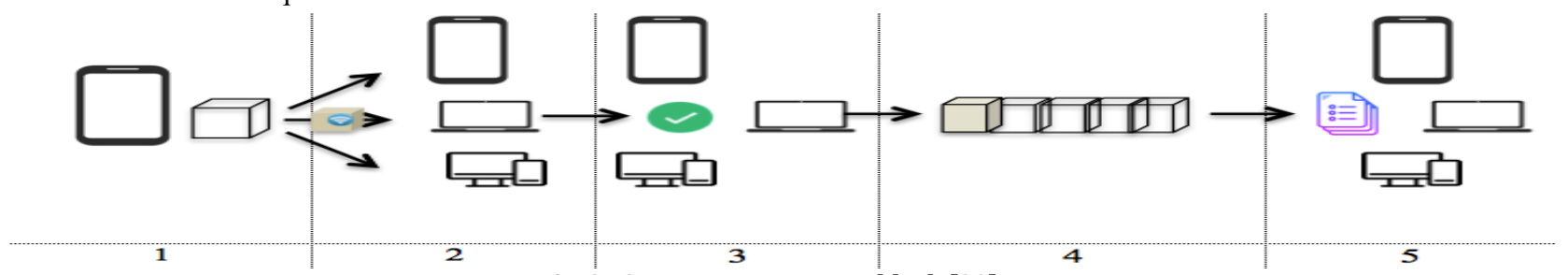

Fig. 2 : Steps to create a new block [23] of this decentralization given the non-necessity to evaluate the reliability of the intermediary or the other network participants [22], so the data are easily exploitable and verifiable. Furthermore, adding a new transaction involves more interactions with other nodes in the chain. As illustrated in Fig. 1 , the insertion operation of a new block is characterized by the non-localization of the nodes, the suitability of the operation, and the security of the records. The steps for inserting a new block are:

1) Send a new transaction; new transaction, to all the nodes of the chain;

3) Most nodes approve the new transaction;

4) Add the new block to the chain;

5) Save a new copy of the book containing all the blocks on a network of nodes.
2) Send the block, corresponding to the request for a

\subsection{Smart Contracts}

The term "smart contract" was coined by N. Szabo with the objective of "securing relationships on public networks"[24]. In blockchain networks, smart contracts perform the function of carrying out transactions in a predetermined fashion, agreed upon by parties participating in the contract. While Bitcoin, the first cryptocurrency implementation of the blockchain, does not deploy and execute smart contracts, it does offer limited programmability via a scripting language, which was not userfriendly or Turing-complete [25]. Newer platforms like Ethereum [26] and Hyperledger [27] have smart contract programmability built into them. When deployed, smart contract code is stored in the blockchain, and the functions written in the smart contract can be invoked by any participant at any time.

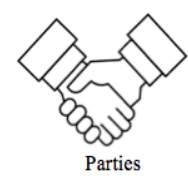

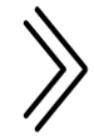

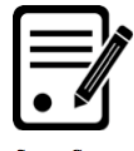

Smart Contract
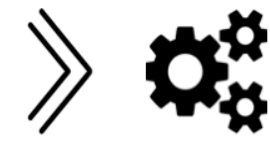

Execution
Fig. 3 : Smart Constract scenario

In addition, Smart Contracts can be used to perform various functions within a blockchain network, such as:

- Allowing storage space for application-specific information;

- Providing utility to other smart contracts;

- Allowing 'multi-signature' transactions, whereby a transaction is only carried out when a majority or a required percentage of participants agree to sign it [28];

- Enabling automated transactions triggered by sspecific events. This functionality can manifest itself in multiple ways, for example, transactions automatically sent over fixed time intervals or transactions sent in response to other transactions. This facilitates request-response type transactions, for decentralized data access within a blockchain-based system. A smart contract can also be triggered when a message is sent to the smart contract's address [29].

\section{The keys to smart Logistics}

Companies face a significant challenge "to act as efficiently as possible". Indeed, material flows and intralogistics processes must harmonize at best at all times. If it gets stuck in one place, the consequences affect the whole value chain and therefore, competitiveness. In Industry 4.0, smart sensors and interconnected systems contribute to efficient logistics processes. The data is collected, processed in real-time and forms the decision-making base of the autonomous and controlled processes. Practical: the constant traceability of goods and processes coupled with intelligent systems makes it possible to autonomously optimize procedures.

- Connectivity: A connected supply chain drives business growth through expanded and integrated digital ecosystems that unite employees, business partners, systems and objects.

- Intelligence: An intelligent supply chain improves the competitiveness with advanced Analytics and Machine Learning features that will optimize and automate your business operations and help you make informed decisions.

- Collaboration: A collaborative supply chain ensures secure and enriched collaboration by enabling employees, business partners, systems and objects to find common solutions for the benefit of all.

- Security: A secure supply chain ensures that only authorized people, systems and objects have access 
to the desired information for a defined period of time.

- The blockchain is designed to provide solutions to complex ecosystems where there is no central actor, where the collaborating actors do not naturally trust each other, where access to the data must be centralized and where the protection of data is essential.

Regardless of the level of financial or ethical maturity of the companies: each of these 5 pillars contributes to transforming their supply chain. Together, they help to stay ahead of the competition and progress in the digital transformation of their supply chain: from the design of new solutions based on analytical lessons to the optimization of the supply logistics network. of their customers. Advanced Analytics, Artificial Intelligence (AI) and Internet of Things (IoT) technologies are paving the way for this transformation. Otherwise, the blockchain offers end-to-end visibility of shipments of goods by tracking each event that concerns a given product. The blockchain traces the documentation and packaging associated with the products, which requires a study of its applications, particularly in smart logistics.

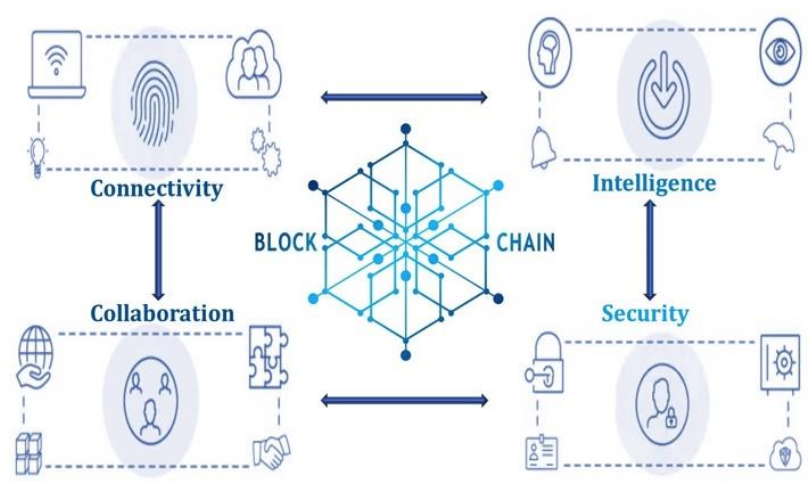

Fig. 4 : The keys to Smart Logistics

\section{Blockchain and Smart contracts in smart Logistics}

Smart logistics is typically defined by the use of new technologies such as IoT, AI, cloud computing, RFID cards, sensors, and actuators. Moreover, it allows a transfer of autonomy, intelligence, and autonomous decision-making machines. The technological revolution and the multitude of data collection components have highlighted the issue of the level of data security, and the reliability of communications

Blockchain's ability, reliability, traceability, and authenticity of the information, as well as intelligent contractual relationships for a trustless environment, foreshadow a major overhaul of supply chains and supply chain management [21]. Additionally, the Blockchain offers considerable potential for improving the logistics process, principally after the trend towards smart logistics, and the use of communication and information technologies at all levels of the value chain. One of the most important aspects of the blockchain application is its interface with the physical world, which requires the appropriate tools and technology, such as IoT [30].

This explains the progressive rate of producers' industrial investments in smart logistics technologies to improve and personalize their offers [31]. According to a recent study of trends in logistics and supply chain management, Blockchain is known only to some logistics experts, and even fewer to those pursuing implementation plans [32]. Also, the use of Blockchain technology in the field of smart logistics remains rare, following its new appearance, its low popularity, and its complexity for the majority of people and organizations. The first real application in the logistics field was announced in April 2015: Everledger startup uses Blockchain to fight fraud in diamond supply chains [33]. This section will explore the applicability and integration of Blockchain technology in the four intelligent logistics sectors.

\subsection{Information}

Information flows are a priority in logistics and the supply chain for a variety of reasons, including ensuring the internal and external communication of the organization (with stakeholders), generating control and decision-making data, collecting large masses of data for forecasting, and classifying feedbacks. The value of this information induces companies to use methods that offer greater security and reliability in their management. Currently, Blockchain technology allows for more secure tracking of all information flows within smart logistics. Blockchain's application to the information clusters, consists of registering each asset as it passes through supply chain nodes, order tracking, receipts, invoices, payments and other official documents, and tracking digital assets (such as warranties, certifications, licenses, serial numbers, barcodes) unified and in parallel with physical assets [34]. These applications are implemented on several projects, such as the mutual project between Microsoft and Mojix. Both companies intend to minimize the differences between databases created by supply chain stakeholders. This would enable them to make their supply chains even more agile by taking or updating their decisions as new data become available [35]. The second example is the grouping of the companies BASF, operating in the field of the chemical industry, and the Fintech Quantoz start-up, as well as the Ahrma group. The goal of the consortium is collecting and sharing of supply chain data in near real-time. It operates on a palette equipped with sensors that write the data in a private blockchain accessible to partners throughout the path [36]. Blockchains can help protect both digital and information assets from being copied, stolen or infringed, thereby adding to the trust levels among agents on the blockchain [48].

Additionally, the monitoring and reporting of information within the supply chain, tracking of data traceability for endusers, and all stakeholders remains important. The decentralization model, public access, and the authenticity of the expedition allow Blockchain technology to meet this need. Two applications of data traceability in smart logistics seem remarkable. The first is the trial led by the grain exporting company $\mathrm{CBH}$, and the Australia-based ArgiDigital start-up: the $\mathrm{CBH}$ group hopes to gain a competitive advantage in Asia by proving that its exported oats are sourced from Australia [37]. The second is to create a traceability application of the provenance of the geological samples by the large mining company BHP Billiton, the original sampling location and the additional manipulation data are immutably recorded on the public channel Ethereum Blockchain [38].

\subsection{Transport}

The applications of Blockchain technology in the transportation field are diverse and varied. Walmart, a supermarket retailer, has recently been granted a patent to improve last-mile logistics by connecting delivery drones to the 
Blockchain [39]. This innovation can be generalized across all agents, operations, and equipment implemented in the last segments of the supply chain. Integrating the Blockchain into shipping or sea transport can increase sustainability, reduce fraud, reduce paperwork delays, reduce waste and identify problems faster. Accordingly, this could increase world GDP by almost $5 \%$ and total trade volume by $15 \%$ [40]. In addition, and according to the information published on DHL's official web pages, up to $10 \%$ of the bills of lading contain incorrect data that can give rise to litigation [41]. Blockchain technology could play an important role in reducing these problems, and improving logistics processes.

\subsection{Finance}

The first Blockchain has been applied in the finance to serve as a base for Bitcoin cryptocurrency. The latter uses P2P technology and operates without any trusted third-party authority that may appear as a bank, commissioned accountant (CA), notary or another centralized service [42]. In general, cryptocurrency aims the finalization of payments in the absence of intermediate actors, as well as the minimization see the absence of the charges of movement of the funds.

The Blockchain can be used in various financial services such as remittances, and online payments. These services affect supply chain processes and product management, as well as financial transactions between different parts of the network [43]. In addition, they will improve business processes by simplifying the process of acquiring products and services by exceeding currency constraints and transfer charges. As well as encouraging customers and improving their demands.

\subsection{Management}

The Blockchain integration in smart logistics allows the improvement of logistics processes, which positively affects the management, and will make the chains even more agile. In addition, data collecting and its transmitting in near real-time gives managers clear visibility of the operating status of the whole processes and allows them to make timely decisions based on reliable data. For example, Kshetri [44] uses a multiple case study method to study the impact of the blockchain on various supply chain management objectives. Furthermore, Saberi [45] explores the major obstacles to adopt blockchains, particularly smart contracts, to achieve sustainable supply chain management objectives. An example of blockchain application for IoT stsemes is to distribute messages between devices in a chain where each message is treated similarly to a transaction.

Smart contracts are rules stored on blocks, capable of arranging financial arrangements and ensuring that sufficient funds are available for projects and that everyone is paid on time [46]. Smart contracts influence network data sharing between supply chain participants and continuous process improvement [21]. Thus, they provide a connection for transactions between different currencies or mix them from multiple sources in the global supply chain in a secure and fast manner [47].

\section{Discussion}

Our study revealed valuable applications of Blockchain technology in the context of smart logistics. The four clusters presented above, provide an overview of the important spots of these applications. However, this is only a primary categorization of various recent efforts. However, we can see that these applications affect different dimensions of organisms and affect their economic performance. Inclusively, one of the most important aspects of the blockchain application is its interface with the physical world, which will require the tools and the appropriate technology such as IoT, this integration will be a strong motivation to adopt the blockchain technology. The most aspiring benefits and risks of applying blockchain technology in the field of smart logistics are presented in Table 1. We note that the blockchain represents an opportunity to improve traceability, confidence, and the speed of operations between stakeholders of smart logistics. Besides its motivation, the blockchain is still immature, there is no standard or standardization body which creates insecurity between stakeholders. In addition, prospects for future research have been identified and presented.

\begin{tabular}{|c|c|c|}
\hline Gains & Risks & $\begin{array}{c}\text { Research } \\
\text { challenges }\end{array}$ \\
\hline 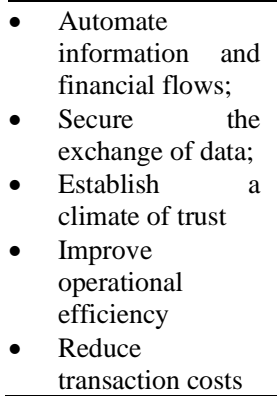 & $\begin{array}{l}\text { - High power } \\
\text { consumption, } \\
\text { and CPU } \\
\text { power; } \\
\text { Absorption of } \\
\text { hard disk } \\
\text { capacity; } \\
\text { Absence of } \\
\text { legislation, and } \\
\text { standards of } \\
\text { use. }\end{array}$ & $\begin{array}{l}\text { - Study and design of } \\
\text { integration and } \\
\text { interaction schemes } \\
\text { of blockchain, IoT, } \\
\text { and IA } \\
\text { technologies in } \\
\text { smart logistics; } \\
\text { - Proposed norms } \\
\text { and communication } \\
\text { APIs between } \\
\text { blockchain. }\end{array}$ \\
\hline
\end{tabular}

\section{Conclusion}

The purpose of our study was to determine Blockchain trends and applications in smart logistics, as well as to present concrete examples of these applications. This work was done by classifying the application according to four clusters. As far as smart logistics are concerned, blockchain-based technology is still a subject of several research studies. In fact, there is an enormous interest in Blockchain applications and hence numerous companies are working on them.

Blockchain can facilitate logistics tasks: it can be used to track purchase orders, order changes, freight documents, and it can help in information sharing about logistic process and delivery. The blockchain technology has huge potential for development and application in the smart logistics sector, presenting challenges for further research. Consequently, more research is needed. For example, Study and design of integration and interaction schemes of blockchain, IoT, and IA technologies in smart logistics, proposed norms and communication APIs between blockchain. Furthermore, the financial evaluation of the application of blockchain technology in smart logistics, the level of energy consumption, energy efficient transactions, and block generation time.

The trends and application of Blockchain has several limitations, and prospects for improvement when applied in the field of smart logistics. Namely: the development of data standardization standards, to simplify exchanges between the different channels. In addition, the preparation and implementation of regulatory laws, in order to have a climate of trust. 


\section{References}

[1] SA Abeyratne, RP Monfared. 2016. "Blockchain Ready Manufacturing Supply Chain Using Distributed Ledger". In: International Journal of Research in Engineering and Technology 5.9, pp. 1-10 https://doi.org/10.15623/ijret.2016.0509001 .

[2] F Tian. 2017. "A Supply Chain Traceability System for Food Safety based on HACCP, Blockchain \& Internet of Things." International Conference on Service Systems and Service Management (ICSSSM).

[3] MC Cooper, ML Douglas, DP Janus. 1997. Supply chain management: More than a new name for logistics International Journal of Logistics Management, 8(1), 114. https://doi.org/10.1108/09574099710805556

[4] Council of Supply Chain Management Professionals. 2005. Supply Chain Management/ Logistics Management Definitions.

[5] C Koo, F Ricci, C Cobanoglu, F Okumus. 2017. Special issue on smart, connected hospitality and tourism. Information Systems Frontiers, 19(4), 699-703. https://doi.org/10.1007/s10796-017- 9776-9 .

[6] A El-Kassar, SK Singh. 2018. Green innovation and organizational performance: The influence of big data and the moderating role of management commitment and HR practices. Technological Forecasting and Social Change, (Accepted \& in Press). https://doi.org/10.1016/j.techfore.2017.12.016

[7] K Butner. 2010. The smarter supply chain of the future. Strategy and Leadership, 38(1), 22-23. https://doi.org/10.1108/10878571011009859

[8] H Kaur. SP Singh. 2017. Flexible dynamic sustainable procurement model. Annals of Operations Research, 273, 1-41. https://doi.org/10.1007/s10479-017-2434-2

[9] S Mallik. 2010. The Handbook of Technology Management: Supply Chain Management, Marketing and Advertising, and Global Management (Hossein Bidgoil. ed.), vol 2 (1 ed.). Hoboken, New Jersey: John Wiley \& Sons, Inc.

[10] C Wong, H Skipworth, J Godsell, N Achimugu. 2012. Towards a theory of supply chain alignment enablers: a systematic literature review. Supply Chain Management: An International Journal, 17/4, pp. 419437. https://doi.org/10.1108/13598541211246567

[11] K Butner. 2010. The smarter supply chain of the future. Strategy and Leadership, Vol. 38, No. 1, pp. 22-31. https://doi.org/10.1108/10878571011009859

[12] L Wu, X Yue, A Jin, DC Yen. 2016. Smart supply chain management: a review and implications for future research. The International Journal of Logistics Management, Vol. 27 Issue: 2, pp.395417, https://doi.org/10.1108/IJLM-02-2014-0035. https://doi.org/10.1108/IJLM-02-2014-0035

[13] K Windt, F Böse, T Philipp. 2008. "Autonomy in Production Logistics: Identification, Characterisation and Application." International Journal of Robotics and Computer Integrated Manufacturing 24 (4): 572-578. https://doi.org/10.1016/j.rcim.2007.07.008

[14] F Kache, S Seuring. 2017. "Challenges and Opportunities of Digital Information at the Intersection of Big Data Analytics and Supply Chain Management." International Journal of Operations \& Production $\begin{array}{llll}\text { Management } & 37 & \text { (1): } \quad 10-36 .\end{array}$ https://doi.org/10.1108/IJOPM-02-2015-0078

[15] D McFarlane, V Giannikas, W Lu. 2016. "Intelligent logistics: Involving the customer," Computers in
Industry, vol. 81, pp. 105-115, Sep. https://doi.org/10.1016/j.compind.2015.10.002

[16] D Uckelmann. 2008. "A Definition Approach to Smart Logistics," Lecture Notes in Computer Science, pp. 273-284. https://doi.org/10.1007/978-3-540-855002__28

[17] Strandhagen, J Ola, LR Vallandingham, G Fragapane, JW Strandhagen, ABH Stangeland, N Sharma. 2017. "Logistics 4.0 and Emerging Sustainable Business Models." Advances in Manufacturing 5 (4): 359-369. https://doi.org/10.1007/s40436-017-0198-1

[18] L Barreto, A Amaral, T Pereira. 2017. "Industry 4.0 Implications in Logistics: An Overview." Procedia Manufacturing 13: 1245- 1252 https://doi.org/10.1016/j.promfg.2017.09.045

[19] Timm, J Ingo, F Lorig. 2015. "Logistics 4.0 - A Challenge for Simulation." In Proceedings of the 2015 Winter Simulation Conference, edited by L. Yilmaz, W. K. V. Chan, I. Moon, T. M. K. Roeder, C. Macal, and M. D. Rossetti, 3118-3119. Huntington Beach, CA https://doi.org/10.1109/WSC.2015.7408428

[20] M Crosby, P Pattanayak, S Verma, V Kalyanaraman. 2016. "Blockchain Technology: Beyond Bitcoin." Applied Innovation 2: 6-9.

[21] S Saberi, M Kouhizadeh, J Sarkis, L Shen. 2018. Blockchain technology and its relationships to sustainable supply chain management. Taylor \& Francis https://doi.org/10.1080/00207543.2018.1533261

[22] M Nofer, P Gomber, O Hinz, and D Schiereck. 2017. "Blockchain." Business \& Information Systems $\begin{array}{llll}\text { Engineering } & 59 & \text { (3): } & 183-187 .\end{array}$ https://doi.org/10.1007/s12599-017-0467-3

[23] Y Issaoui, A Khiat, A Bahnasse, H Ouajji. 2019. Smart logistics : Study of the application of blockchain technology. Procedia Computer Science 160 (2019) 266-271.

Elsevier.

https://doi.org/10.1016/j.procs.2019.09.467

[24] N Szabo. 1997. "Formalizing and securing relationships on public networks," First Monday, vol. 2, no. 9. https://doi.org/10.5210/fm.v2i9.548

[25] F Tschorsch, B Scheuermann. 2016. "Bitcoin and beyond: A technical survey on decentralized digital currencies," IEEE Communications Surveys \& Tutorials, vol. 18, no. 3, pp. 2084-2123, thirdquarter. https://doi.org/10.1109/COMST.2016.2535718

[26] G Wood. 2014. "Ethereum: A secure decentralised generalised transaction ledger," Ethereum Project Yellow Paper, vol. 151.

[27] V Dhillon, D Metcalf, and M Hooper. 2017. "The hyperledger project," in Blockchain Enabled Applications, pp. 139-149. https://doi.org/10.1007/9781-4842-3081-7_10

[28] S. Omohundro. 2014. "Cryptocurrencies, smart contracts, and artificial intelligence," AI matters, vol. 1, no. 2, pp. 19-21. https://doi.org/10.1145/2685328.2685334

[29] L Luu, DH Chu, H Olickel, P Saxena, and A Hobor. 2016. "Making smart contracts smarter," in Proc. of the ACM SIGSAC Conference on Computer and Communications Security, pp. 254-269. https://doi.org/10.1145/2976749.2978309

[30] C Catallini. 2017. "How Blockchain ApplicationsWill Move Beyond Finance." Harvard Business Review 2. https://hbr.org/2017/03/howblockchain- applicationswill-move-beyond-finance.

[31] Seebacher, S.; Schüritz, R. 2017. Blockchain Technology as an Enabler of Service Systems: A 
Structured Literature Review. Springer Nature, 279, 12-23. https://doi.org/10.1007/978-3-319-56925-3_2

[32] W Kersten, M Seiter, BV See, $N$ Hackius, and $T$ Maurer. 2017. Trends and Strategies in Logistics and Supply Chain Management - Digital Transformation Opportunities. Hamburg: DVV Media Group.

[33] M Petersen, N Hackius, BV See. 2017. Mapping the Sea of Opportunities: Blockchain in Supply Chain and Logistics

[34] E Tijan, S Aksentijevi, K Ivani, M Jardas. 2019. Blockchain Technology Implementation in Logistics. Sustainability https://doi.org/10.3390/su11041185

[35] Michael del Castillo. 2017. Microsoft Unveils Project Manifest, A Plan For Blockchain Product Tracking. CoinDesk, January 2017.

[36] Susan Lace_eld. 2017. Pilot project connects blockchain and martpallets. CSCMP's Supply Chain Quarterly, September 2017.

[37] Wol_e Zhao. 2017. Australia's Biggest Grain Exporter Trials Blockchain Tracking System. Coindesk, August 3rd, 2017.

[38] Pete Rizzo. 2016. World's Largest Mining Company to Use Blockchain for Supply Chain. Coindesk, September 23rd, 2016.

[39] Hackett, R. 2017. Wal-Mart Explores Blockchain for Delivery Drones.

[40] World Economic Forum's Report. 2018. Enabling Trade. Valuing Growth Opportunities. Geneva. Available online: http://www3.weforum.org/docs/WEF_SCT_EnablingTr ade_Report_2013.pdf (accessed on 14 May 2018).

[41] DHL Trend Research Blockchain in Logistics; Perspectives on the Upcoming Impact of Blockchain Technology and use Cases for the Logistics Industry. Available online: https://www.logistics.dhl/content/dam/dhl/global/core/d ocuments/pdf/glo-core-blockchain-trend-report.pdf (accessed on 16 January 2019).

[42] AP Moller, Maersk (MAERSKb.CO) and IBM (NYSE: IBM). Available online: https://www03.ibm.com/press/us/en/pressrelease/53602.wss (accessed on 20 February 2019).

[43] E Hofmann, UM Strewe, and N Bosia. 2018. "Discussion - How Does the Full Potential of Blockchain Technology in Supply Chain Finance Look Like?" In Supply Chain Finance and Blockchain Technology, 77-87. Cham: Springer. https://doi.org/10.1007/978-3-319-62371-9_6

[44] N Kshetri. 2018. "Blockchain's Roles in Meeting Key Supply Chain Management Objectives." International Journal of Information Management 39: 80-89. https://doi.org/10.1016/j.ijinfomgt.2017.12.005 .

[45] Saberi, S., M. Kouhizadeh, J. Sarkis, and L. Shen. 2019. "Blockchain Technology and Its Relationships to Sustainable Supply Chain Management." International Journal of Production Research 57 (7): 2117-2135. https://doi.org/10.1080/00207543.2018.1533261

[46] E Hofmann, UM Strewe, and N Bosia. 2017. Supply Chain Finance and Blockchain Technology: The Case of Reverse Securitisation. Cham: Springer. https://doi.org/10.1007/978-3-319-62371-9

[47] I Eyal. 2017. "Blockchain Technology: Transforming Libertarian Cryptocurrency Dreams to Finance and Banking Realities." Computer 50 (9): 38-49. https://doi.org/10.1109/MC.2017.3571042

[48] Steininger, D. M. 2019. "Linking Information Systems and Entrepreneurship: A Review and Agenda for ItAssociated and Digital Entrepreneurship Research." Information Systems Journal 29 (2): 363-407. https://doi.org/10.1111/isj.12206 